\title{
PHYSICAL ACTIVITY PATTERNS AND SEDENTARY BEHAVIORS OF CHILDREN FROM URBAN AND RURAL AREAS OF CYPRUS
}

\author{
Eirini Bathrellou, Chrystalleni Lazarou, Demosthenes B. Panagiotakos, Labros S. Sidossis \\ Department of Nutrition - Dietetics, Harokopio University, Athens, Greece
}

\section{SUMMARY}

Background: A sedentary lifestyle among children is becoming increasingly common and has been linked to future risk of degenerative diseases. Urban residence has been suggested to be a contributing factor to a less active lifestyle; however, not all available studies support this link. In the present study we examined the physical activity patterns and sedentary behaviours of children living in urban and rural areas of Cyprus, where major demographic shifts have occurred the last decades.

Methods: We studied 1140 children (531 boys; 609 girls), aged 10-12 years, registered in 24 selected elementary public schools from five urban and rural districts of Cyprus. Children completed a semi-quantitative physical activity questionnaire regarding frequency and duration of everyday physical and sedentary activities. Weight and height of the children, as well as demographic and socioeconomic information was collected from children and their guardians.

Results: Rural children reported being slightly more active after school and occupied weekly with outdoors chores compared to urban children, who on the other hand reported engaging in sports on a weekly basis more than their rural peers (all $p<0.10$ ). However, the average weekly time spent by urban and rural children on vigorous ( $8.6 \pm 4.7$ and $9.1 \pm 4.8 \mathrm{~h} / \mathrm{w}$, respectively; $p=0.193)$ or moderate-to-vigorous $(14.9 \pm 7.6$ and 15.2 $\pm 7.6 \mathrm{~h} / \mathrm{w}$, respectively; $p=0.612$ ) activities, as well as total screen time, were not different. The distribution of children with regards to most other physical activity and inactivity pursuits was similar between urban and rural areas.

Conclusion: We found no substantial differences in the physical activity habits and sedentary behaviours among children living in urban and rural areas of Cyprus. Hence public health awareness directed to enhance physical activity and decrease sedentary lifestyle among youngsters should focus equally to urban and rural children.

Key words: children, sedentary lifestyle, physical activity, urban, rural, Cyprus

Address for correspondence: L. S. Sidossis, Harokopio University, El. Venizelou 70, 17671 Athens, Greece E-mail: Isidossis@hua.gr

\section{INTRODUCTION}

Low levels of physical activity and a sedentary lifestyle among children have been implicated in the development of cardiovascular disease, obesity, hypertension, type 2 diabetes and other chronic diseases later in life (1-4). Many studies examining secular trends in physical activity patterns in children reveal that a less physically active or a more sedentary lifestyle is becoming increasingly common (5-7); from a public health perspective, these observations are worrisome in terms of future risk for chronic diseases. These trends may be related to changes in physical and social environment stemming from urbanisation, which is not only recognized as the most important demographic shift worldwide during the past century, but is also an ongoing process leading nearly two-thirds of the world's population to be living in urban areas within the next 30 years (8).

Whereas better living conditions have been shown to offer a potential advantage for improved physical fitness in urban compared to rural children $(9,10)$, nevertheless, urban residence has been linked to sedentary lifestyle due to lack of adequate space for play, concerns for safety, automatic transportation and computerisation of many activities (11). This uncertainty is reflected on the results from several studies that investigated physical activity patterns and sedentary behaviors of urban and rural children, which have been inconsistent: some have shown that urban children adopt a more sedentary lifestyle and have higher prevalence of overweight and obesity compared to their rural peers (12-14), whereas others found no differences and concluded that the place of residence, urban or rural, is not a major factor determining the physical activity patterns of children (15-17).

In Cyprus, major demographic changes and rapid urbanization of a large proportion of the population have occurred during the last three decades. The impact that these demographic changes may have had on the lifestyle of children is unknown. It was the aim of the present study, therefore, to examine the physical activity-related behaviors of children living in urban and rural areas of Cyprus.

\section{METHODS}

\section{Participants}

The study sample consisted of 1140 children (531 boys and 609 girls), aged $10-12$ years, registered in the $4^{\text {th }}, 5^{\text {th }}$, and $6^{\text {th }}$ grades 
of 24 elementary public schools from 5 districts of the Republic of Cyprus. Out of 1,589 children originally selected, $72 \%$ participated in the study. Sampling was multistage and stratified, and sample size accounted for $3.7 \%$ of the total population studied (2.6\% for urban area of Lefkosia, $7.8 \%$ for rural area of Pafos). Urban and rural areas were classified as such according to data from the National Statistical Service. Urban children accounted for $55.7 \%(n=635)$ and boys for $46.7 \%(n=531)$ of the whole sample. The study was approved by the Ministry of Education and Culture of Cyprus, and consent for the children's participation was obtained from their parents or legal guardians.

\section{Measurements}

The children completed a semi-quantitative, physical activity questionnaire during regular school hours. Information was collected on the frequency and duration of everyday physical and sedentary activities on the weekdays, the weekend, and on the previous day, using an 8-level answer scale ranging from " 0 " to "more than 8 hours" per day or week. For assessing the time spent to individual physical activities, a 4-level answer scale ranging from " 0 times per week" to "more than 6 times per week" was used. Physical activities, like bicycling, basketball, racket sports, volleyball, running, soccer, swimming, etc., were classified as moderate or vigorous according to MET (Metabolic Equivalent Task) scores: activities of 3-6 METs were classified as moderate and those of more than 6 METs were classified as vigorous,

Table 1. Demographic characteristics of the study sample

\begin{tabular}{|c|c|c|c|c|}
\hline & Total & Urban & Rural & $p$ \\
\hline $\mathrm{N}$ & 1140 & $635(55.7)$ & 505 (44.3) & \\
\hline Male sex & $531(46.7)$ & $291(46)$ & $240(47.5)$ & 0.602 \\
\hline Age (years) & $10.67(0.98)$ & $\begin{array}{l}10.72 \\
(0.99)\end{array}$ & $10.61(0.96)$ & 0.241 \\
\hline Ethnicity & & & & $<0.001$ \\
\hline $\begin{array}{l}\text { Greek } \\
\text { Foreign } \\
\text { Mixed }\end{array}$ & $\begin{array}{l}887(88.3) \\
33(3.3) \\
84(8.4)\end{array}$ & $\begin{array}{l}466(84.3) \\
30(5.4) \\
57(10.3)\end{array}$ & $\begin{array}{l}421(93.3) \\
3(0.7) \\
27(6)\end{array}$ & \\
\hline Place of birth & & & & $<0.001$ \\
\hline $\begin{array}{l}\text { Rural } \\
\text { Suburban } \\
\text { Urban }\end{array}$ & $\begin{array}{l}197(19.9) \\
67(6.8) \\
728(73.4)\end{array}$ & $\begin{array}{l}18(3.2) \\
51(9.1) \\
494(87.7)\end{array}$ & $\begin{array}{l}179(41.7) \\
16(3.7) \\
234(54.5)\end{array}$ & \\
\hline Place of upbringing & & & & $<0.001$ \\
\hline $\begin{array}{l}\text { Rural } \\
\text { Suburban } \\
\text { Urban }\end{array}$ & $\begin{array}{l}444(45.2) \\
77(7.8) \\
462(47)\end{array}$ & $\begin{array}{l}20(3.6) \\
74(13.5) \\
455(82.9)\end{array}$ & $\begin{array}{l}424(97.7) \\
3(0.7) \\
7(1.6)\end{array}$ & \\
\hline \multicolumn{5}{|l|}{ Place of current living } \\
\hline $\begin{array}{l}\text { Rural } \\
\text { Suburban } \\
\text { Urban }\end{array}$ & $\begin{array}{l}442(45.3) \\
91(9.3) \\
442(45.3)\end{array}$ & $\begin{array}{l}19(3.5) \\
89(16.2) \\
440(80.3)\end{array}$ & $\begin{array}{l}423(99.1) \\
2(0.5) \\
2(0.5)\end{array}$ & \\
\hline Type of residence & & & & $<0.001$ \\
\hline $\begin{array}{l}\text { Apartment } \\
\text { House with yard } \\
\text { House without yard }\end{array}$ & $\begin{array}{l}151(13.8) \\
886(80.7) \\
61(5.6)\end{array}$ & $\begin{array}{l}138(23) \\
430(71.7) \\
32(5.3)\end{array}$ & $\begin{array}{l}13(2.6) \\
456(91.6) \\
29(5.8)\end{array}$ & \\
\hline Living in a refugee camp & $74(6.99)$ & $57(10)$ & $17(3.5)$ & $<0.001$ \\
\hline Own residence & $964(90)$ & $483(83.7)$ & $481(97.4)$ & $<0.001$ \\
\hline Home-maid service & $331(29.9)$ & $239(39.4)$ & $92(18.4)$ & $<0.001$ \\
\hline
\end{tabular}

Continuous variables are presented as mean $( \pm \mathrm{SD})$, and categorical variables as frequencies and percentages in parentheses. based on Ainsworth et al. (18). Questions about physical activity lifestyle and behaviors (e.g., commuting to school) were also included, having 4 qualitative frequencies as possible answers: "rarely/never", "sometimes", "most times", and "always". The same investigator gave all questionnaires, and all children received the same instructions on how to complete them.

Data were also collected from the parents of 1,068 children regarding demographic, social, and economic characteristics, as well as physical activity-related behaviors and attitudes of their children. The weight and height of the children were obtained from their parents by self-report, and body mass index (BMI) was calculated. Overweight and obesity were identified by using the age- and sex-specific BMI cut-off points for children and adolescents adopted by the International Obesity Task Force (19).

\section{Data Analysis}

Results are presented as mean $\pm \mathrm{SD}$ or absolute and relative frequencies. All variables were tested for normality using the Kolmogorov-Smirnov criterion. Differences between urban and rural children were assessed with the Student independent t-test for normally distributed variables, and the Mann-Whitney U-test for not normally distributed variables. The $\chi^{2}$ test of independence was performed to examine differences in categorical variables. Due to multiple comparisons made the Bonferroni rule was applied to account for the inflation of type-I error. Statistical analysis was performed with SPSS 12 (SPSS Inc., Chicago, IL).

\section{RESULTS}

The basic demographic characteristics of the sample are presented in Table 1. Mean age of the children was $10.7 \pm 0.9 \mathrm{yr}$, and was not different between urban and rural children. Statistically significant differences between groups were found with respect to ethnicity, current and former place of living, type of residence, and availability of home-maid service (Table 1).

Rural children reported spending significantly more time in physical activity (of any kind) after school hours than did urban children ( $2.2 \pm 1.9$ vs. $2.0 \pm 1.8 \mathrm{~h} / \mathrm{d}$, respectively; $\mathrm{p}=0.056)$, although both groups were similarly active after school the previous day $(1.4 \pm 1.6$ vs. $1.4 \pm 1.7 \mathrm{~h} / \mathrm{d}$, respectively; $\mathrm{p}=0.164)$. Rural children reported being more occupied with outdoor chores during the week $(1.5 \pm 1.5$ vs. $1.3 \pm 1.3 \mathrm{~h} / \mathrm{w}$, respectively; $\mathrm{p}=0.081)$, whereas no difference was found regarding time spent on home chores $(1.4 \pm 1.3$ vs. $1.5 \pm 1.6 \mathrm{~h} / \mathrm{w}$, respectively; $\mathrm{p}=0.911)$. On the other hand, urban children were engaged more in sports (after school) than rural children the previous day $(1.1 \pm 1.5 \mathrm{vs.} 1.0 \pm 1.3$ $\mathrm{h} / \mathrm{d}$, respectively; $\mathrm{p}=0.078$ ). The average weekly time spent on vigorous activities did not differ between urban and rural children $(8.6 \pm 4.7$ vs. $9.1 \pm 4.8 \mathrm{~h} / \mathrm{w}$, respectively; $\mathrm{p}=0.193)$. Similarly, no differences were found for the average weekly time spent on moderate-to-vigorous activities (urban children: $14.9 \pm 7.6 \mathrm{~h} / \mathrm{w}$ and rural children: $15.2 \pm 7.6 \mathrm{~h} / \mathrm{w}, \mathrm{p}=0.612$ ).

The distribution of the children at different categories of various physical activity pursuits is shown in Table 2 . The percentage of children participating in physical education classes at school, in the public physical education programme Sports For All (SFA), and in sports after school (on weekly basis or the previous day) did not differ between urban and rural children. The proportions 
Table 2. Comparison of physical activity pursuits in urban and rural children

\begin{tabular}{|l|l|l|l|}
\hline & Urban & Rural & p \\
\hline \% of participants in physical education classes at school & 98.8 & 98.4 & 0.525 \\
\hline \% of participants in pubic physical education programme (SFA) in weekly basis & 13.1 & 11.2 & 0.349 \\
\hline \% of participants in sports after school & 96.5 & 98.5 & 0.118 \\
\hline \% of those who engage in sports after school up to 2 h/w & 60.8 & 67.2 & 0.110 \\
\hline \% of those who engaged in sports the day before & 64.5 & 61.8 & 0.362 \\
\hline \% of those who participate in any physical activity after school (except sports) & 89.1 & 93.9 & 0.05 \\
\hline \% of those who participate in physical activity after school up to 2 h/d (except sports) & 62.3 & 59 & 0.261 \\
\hline \% of those who were physically active the day before (except sports) & 73.7 & 79.8 & 0.018 \\
\hline \% of those who participated in any after school physical activity the day before up to 1 h & 51 & 48.4 & 0.389 \\
\hline \% of those doing any home chores & 98.1 & 99.2 & 0.476 \\
\hline \% of those doing any outdoors chores & 90.8 & 98.1 & $<0.001$ \\
\hline \% of those doing outdoors chores up to 1 h/w & 52.3 & 50.3 & 0.637 \\
\hline
\end{tabular}

Table 3. Screen time in urban and rural children

\begin{tabular}{|l|l|l|l|}
\hline & Urban & Rural & $\mathbf{p}$ \\
\hline Hours per day watching TV/video/DVD in a weekday & $3(2.1)$ & $3.1(2.2)$ & 0.403 \\
\hline Hours per day watching TV/video/DVD in the weekend & $4.3(2.7)$ & $4.2(2.7)$ & 0.310 \\
\hline Hours watching TV/video/DVD yesterday & $2.4(2)$ & $2.3(1.9)$ & 0.331 \\
\hline Hours per day playing with PC or video/electronic games in a weekday & $1.6(1.9)$ & $1.7(1.9)$ & 0.309 \\
\hline Hours per day playing with PC or video/electronic games in the weekend & $2.2(2.4)$ & $2.2(2.4)$ & 0.990 \\
\hline Hours playing with PC or video/electronic games yesterday & $0.8(1.4)$ & $0.8(1.4)$ & 0.275 \\
\hline
\end{tabular}

Values are presented as mean $\pm S D$.

of rural children who engaged in physical activity after school (of any kind except sports) and were physically active the previous day were greater compared to urban children $(p=0.05$ and $p=0.018$, respectively). However, due to multiple comparisons made, the aforementioned differences were not significant after correcting the probability of type I error (i.e., p-value) using the Bonferroni rule, (corrected $p=0.45$ and corrected $p=0.19$, respectively).

Regarding physical inactivity behaviors, screen time (defined as the time devoted to occupation with TV, computer, and electronic or video games) during the weekdays, the weekends, as well as the previous day did not differ between urban and rural children (Table 3). Similarly, time devoted to homework study after school did not differ between the two groups, neither on weekdays $(1.8 \pm 1.2 \mathrm{vs} .1 .9 \pm 1.3 \mathrm{~h} / \mathrm{d}$, respectively for urban and rural children, $\mathrm{p}=0.300)$ nor on weekends $(1.3 \pm 1.4$ vs. $1.3 \pm 1.3$ $\mathrm{h} / \mathrm{d}$, respectively for urban and rural children, $\mathrm{p}=0.874$ ). However, children of urban areas attended more private lessons after school, e.g. for studying foreign languages or music, compared to rural children $(3.0 \pm 2.2$ vs. $2.5 \pm 1.7 \mathrm{~h} / \mathrm{d}$, respectively, $\mathrm{p}=0.003)$. With regards to other sedentary activities, similar proportions of urban and rural children reported sleeping at night more than 8 h ( $54.5 \%$ vs. $52.4 \%$, respectively; $\mathrm{p}=0.457)$, and not taking an afternoon nap at school period $(80.9 \%$ vs. $83.9 \%$, respectively; $\mathrm{p}=0.224)$. On the other hand, and as far as recreational activities are concerned, significantly more urban children reported going to the cinema or theatre (on a weekly basis) than rural ones $(50.2 \%$ vs. $28.4 \%$, respectively; $\mathrm{p}<0.001)$.

With respect to physical activity attitudes and behaviors, more urban than rural children reported having a TV set in their bed- room $(40.2 \%$ vs. $28.6 \%$, respectively; $\mathrm{p}<0.001)$, owning a PC ( $35.5 \%$ vs. $25.7 \%$, respectively; $\mathrm{p}<0.001)$, and having exercise equipment at home $(62.7 \%$ vs. $56.9 \%$, respectively; $p=0.049)$. On average, urban children had a greater number of TV sets compared with rural children ( $2.9 \pm 1.3$ vs. $2.5 \pm 1.0$, respectively; $\mathrm{p}<0.001$ ), and similar results were obtained for the number of PCs $(1.4 \pm 1$ vs. $1.1 \pm 0.8$, respectively; $\mathrm{p}<0.001)$. On the other hand, more rural than urban children reported going to school by car or bus at least sometimes a week $(81.8 \%$ vs. $77.4 \%$, respectively; $p=0.085$ ), while the percentage of children going to school on foot or with their bicycle at least sometimes a week did not differ between urban and rural children $(35.9 \%$ and $37.4 \%$, respectively; $p=0.660$ ). Almost one-third of the parents of both urban and rural children reported that they do not regularly take their child to play $(29.8 \%$ vs. $30.6 \%, p=0.179)$, while more rural than urban parents reported that there is an available playground in the neighbourhood ( $93.4 \%$ vs. $73.8 \%$, respectively; $\mathrm{p}<0.001)$. More than half of both urban and rural children reported engaging in physical activity while being with peers, and not alone $(57.8 \%$ vs. $62.1 \%$, respectively; $\mathrm{p}=0.141)$.

The prevalence of normal weight, overweight and obesity did not differ between urban $(75.9 \%, 19.6 \%$, and $4.6 \%$, respectively) and $\operatorname{rural}\left(78.8 \%, 17.4 \%\right.$, and $3.9 \%$, respectively) areas $\left(\chi^{2}=0.996\right.$, $\mathrm{p}=0.608)$. Sensitivity analysis within the overweight/obese category revealed no differences between urban and rural children in regards to most of the abovementioned parameters, i.e. time spent on vigorous or moderate-to-vigorous activities, distribution of children at various physical activity pursuits, and screen time at all time points (data not shown). 


\section{DISCUSSION}

We examined the physical activity patterns and sedentary behaviours of urban and rural children living in Cyprus. Our findings suggest that although some differences may exist between children residing in urban and rural areas (e.g. time spent on physical activities in general, outdoor chores, and sports), their magnitude was rather small; hence the observed differences are not likely to influence the physical activity patterns of the children in a physiologically significant manner.

Our findings are in accordance with those from other studies showing no differences in physical activity habits between urban and rural children. Similar percentages of students classified as sedentary, moderately or very active, were reported by Plotnikoff et al., in Canada (15). These authors also found that rural children were at the same or even higher risk for being overweight or obese. Similar findings were reported by Tognarelli et al., in Italy, who concluded that physical activity choices of rural children mirrored those of urban children (16). The time spent on TV watching or videogames playing, as well as sports attendance and free time activities were not different between urban and rural children.

Another study conducted in Cyprus found that urban children were more active during the winter, while the reverse was true during summer time (20). This pattern was attributed to the greater engagement of urban children with sports activities on one hand, and the greater opportunity of rural children for outdoors playing on the other. On the whole, however, there were no differences between children from urban and rural areas. Although this finding is not directly comparable to our data, which were collected during spring (from February to June), we also observed that rural children were more physically active after school, whereas urban children spent more time in sports activities. However, for any given parameter that was found to differ between urban and rural children, the size of the difference was rather small, translated to approximately $10 \mathrm{~min}$ or less. We believe that such differences in the allocation of physical activity time are not likely to be physiologically relevant.

Furthermore, all sedentary pursuits examined, and especially screen time which is positively related to childhood adiposity $(7,21,22)$, did not differ between urban and rural children. It is important to point out that the mean screen time substantially exceeded the recommended screen time of 2 hours per day set by the American Academy of Pediatrics (23), whether for urban or rural children. Therefore, it may be that the small differences found in physical activity pursuits were either not great enough to produce a significantly different pattern of physical activity, or were eventually counterbalanced between urban and rural children. And this was, after all, reflected on the similar prevalence of overweight and obesity.

However, other studies have indeed found differences in the physical and sedentary activity patterns between urban and rural children. Proctor et al. reported that rural children in Cameroon were twice as active as urban children, a difference attributed to work-related physical activity (14). Similarly, in Turkey, fewer urban children were reported to engage in sports activities compared to rural children; urban children also reported spending more time on TV watching than their rural peers (12). These differences in physical and sedentary activity habits were also related to differences in adiposity between children from urban and rural areas, with the former being more overweight and obese than the latter. Likewise, urban children in Mexico have been reported to be less physically active than their rural counterparts; risk factors such as obesity, high blood pressure, and unfavourable blood lipid profile were also more prevalent in children from urban than rural areas (24).

The findings from the aforementioned studies reveal an interesting pattern, in that differences in physical activity habits between urban and rural children are usually observed in developing countries but not in westernized ones. In developing countries, a more active lifestyle among rural children is probably dictated by environmental factors, as children still have to walk long distances and spend substantial time being occupied with heavy chores (14). The more the social conditions change, however, the milder the difference between children from urban and rural areas is likely to become. As Hakeem et al. reported, activity level of rural children who have access to formal education and television is not different from their urban counterparts (13).

\section{LIMITATIONS}

The present study has several limitations. The cross-sectional design does not allow for establishing causal relationships, due to the potential impact of several confounding factors. For example, socio-economic status of urban and rural children could well be responsible for our results. Moreover, physical activity patterns and sedentary behaviours of urban and rural children were not analyzed according to the degree of urbanization of each area, which has been shown previously to affect the presence and direction of the differences between urban and rural children (13).

\section{CONCLUSION}

In conclusion, we found no substantial differences in the physical activity habits and sedentary behaviours among children living in urban and rural areas of Cyprus. As a physically active lifestyle is consistently listed among the most important factors not only for preventing illness but also for promoting health and well-being (25-27), and its protective effect is recognized since the early childhood (28-30), public health awareness focuses on the ways to foster physical activity in children and adolescents (31-33). To this direction, the findings from the present study draw attention to the need for development and implementation of measures to promote physical activity equally in urban and rural children.

\section{Acknowledgements}

Warm thanks to the participant children and their parents, to the Cyprus Ministry of Education \& Culture (Primary Education Department), and to all the teachers who readily consented to carry out the study during school hours.

The study was partially subsidized by 'Charalambides' dairies and by Cyprus Dietetic Association. 


\section{REFERENCES}

1. International Obesity TaskForce \& European Association for the Study of Obesity. Obesity in Europe: the case for action [position paper]. London: International Obesity TaskForce; 2002.

2. Gidding SS, Dennison BA, Birch LL, Daniels SR, Gilman MW, Lichtenstein $\mathrm{AH}$, et al. Dietary recommendations for children and adolescents: a guide for practitioners: consensus statement from the American Heart Association. Circulation. 2005 Sep 27;112(13):2061-75. Erratum in: Circulation. 2005 Oct 11;112(15):2375.

3. Andersen LB, Harro M, Sardinha LB, Froberg K, Ekelund U, Brage S, et al. Physical activity and clustered cardiovascular risk in children: a cross-sectional study (The European Youth Heart Study). Lancet. 2006 Jul 22;368(9532):299-304.

4. Kosti RI, Panagiotakos DB. The epidemic of obesity in children and adolescents in the world. Cent Eur J Public Health. 2006 Dec;14(4):151-9.

5. Tremblay MS, Barnes JD, Copeland JL, Esliger DW. Conquering childhood inactivity: is the answer in the past? Med Sci Sports Exerc. 2005 Jul;37(7):1187-94.

6. Dollman J, Norton K, Norton L. Evidence for secular trends in children's physical activity behaviour. Br J Sports Med. 2005 Dec;39(12):892-7.

7. Tomkinson GR, Leger LA, Olds TS, Cazorla G. Secular trends in the performance of children and adolescents (1980-2000): an analysis of 55 studies of the $20 \mathrm{~m}$ shuttle run test in 11 countries. Sports Med. 2003;33(4):285-300

8. Galea S, Vlahov D. Urban health: evidence, challenges, and directions Annu Rev Public Health. 2005;26:341-65.

9. Rutenfranz J, Andersen KL, Seliger V, Masironi R. Health standards in terms of exercise fitness of school children in urban and rural areas in various European countries. Ann Clin Res. 1982;14 Suppl 34:33-6.

10. Reyes ME, Tan SK, Malina RM. Urban-rural contrasts in the growth status of school children in Oaxaca, Mexico. Ann Hum Biol. 2003 NovDec;30(6):693-713.

11. International Association for the Study of Obesity (IASO) \& European Association for the Study of Obesity (EASO). Joint response of the International Obesity TaskForce and the European Association for the Study of Obesity to the Commission of the European Communities Green Paper. Promoting healthy diets and physical activity: a European dimension for the prevention of overweight, obesity and chronic diseases. London: IASO, EASO; 2006.

12. Ozdirenc M, Ozcan A, Akin F, Gelecek N. Physical fitness in rural children compared with urban children in Turkey. Pediatr Int. 2005 Feb;47(1):2631.

13. Hakeem R, Thomas J, Badruddin SH. Urbanisation and activity pattern of south Asian children. J Pak Med Assoc. 2002 Sep;52(9):402-7.

14. Proctor MH, Moore LL, Singer MR, Hood MY, Nguyen US, Ellison RC. Risk profiles for non-communicable diseases in rural and urban schoolchildren in the Republic of Cameroon. Ethn Dis. 1996;6(3-4):235-43.

15. Plotnikoff RC, Bercovitz K, Loucaides CA. Physical activity, smoking, and obesity among Canadian school youth. Comparison between urban and rural schools. Can J Public Health. 2004 Nov-Dec;95(6):413-8.

16. Tognarelli M, Picciolli P, Vezzosi S, Isola A, Moretti F, Tommassetto E, et al. Nutritional status of 8-year-old rural and urban Italian children: a study in Pistoia, Tuscany. Int J Food Sci Nutr. 2004 Aug;55(5):381-7.
17. Tsimeas PD, Tsiokanos AL, Koutedakis Y, Tsigilis N, Kellis S. Does living in urban or rural settings affect aspects of physical fitness in children? An allometric approach. Br J Sports Med. 2005 Sep;39(9):671-4.

18. Ainsworth BE, Haskell WL, Whitt MC, Irwin ML, Swartz AM, Strath SJ, et al. Compendium of physical activities: an update of activity codes and MET intensities. Med Sci Sports Exerc. 2000 Sep;32(9 Suppl):S498504.

19. Cole TJ, Bellizzi MC, Flegal KM, Dietz WH. Establishing a standard definition for child overweight and obesity worldwide: international survey. BMJ. 2000 May 6;320(7244):1240-3.

20. Loucaides CA, Chedzoy SM, Bennett N. Differences in physical activity levels between urban and rural school children in Cyprus. Health Educ Res. 2004 Apr;19(2):138-47.

21. Carvalhal MM, Padez MC, Moreira PA, Rosado VM. Overweight and obesity related to activities in Portuguese children, 7-9 years. Eur J Public Health. 2007 Feb;17(1):42-6.

22. Crespo CJ, Smit E, Troiano RP, Bartlett SJ, Macera CA, Andersen RE. Television watching, energy intake, and obesity in US children: results from the third National Health and Nutrition Examination Survey, 19881994. Arch Pediatr Adolesc Med. 2001 Mar;155(3):360-5.

23. American Academy of Pediatrics. Children, adolescents, and television. Pediatrics. 2001 Feb;107(2):423-6.

24. Yamamoto-Kimura L, Posadas-Romero C, Posadas-Sanchez R, ZamoraGonzalez J, Cardoso-Saldana G, Mendez Ramirez I. Prevalence and interrelations of cardiovascular risk factors in urban and rural Mexican adolescents. J Adolesc Health. 2006 May;38(5):591-8.

25. Johnson-Taylor WL, Everhart JE. Modifiable environmental and behavioral determinants of overweight among children and adolescents: report of a workshop. Obesity (Silver Spring). 2006 Jun;14(6):929-66.

26. Wagner N, Kirch W. Recommendations for the promotion of physical activity in children. J Public Health. 2006 Apr;14(2):71-5.

27. Chrysohoou Ch, Pitsavos Ch, Kokkinos P, Panagiotakos DB, Singh SN, Stefanadis C. The role of physical activity in the prevention of stroke. Cent Eur J Public Health. 2005 Sep;13(3):132-6.

28. Logstrup S, editor. Children and young people - the importance of physical activity: a paper published in the context of the European Heart Health Initiative. Brussels: European Heart Health Initiative; 2001.

29. Lotan M, Merrick J, Carmeli E. Physical activity in adolescence. A review with clinical suggestions. Int J Adolesc Med Health. 2005 JanMar; 17(1):13-21.

30. Jedrychowski W, Maugeri U, Flak E, Mroz E, Bianchi I. Cohort study on low physical activity level and recurrent acute respiratory infections in schoolchildren. Cent Eur J Public Health. 2001 Aug;9(3):126-9.

31. Braet C, Van Winckel M. Curbing obesity: prevention and treatment. Eur J Public Health. 2005 Dec;15(6):561-3.

32. Doak CM, Visscher TL, Renders CM, Seidell JC. The prevention of overweight and obesity in children and adolescents: a review of interventions and programmes. Obes Rev. 2006 Feb;7(1):111-36.

33. Lobstein T, Baur LA. Policies to prevent childhood obesity in the European Union. Eur J Public Health. 2005 Dec;15(6):576-9.

Received November 8, 2006 Accepted in revised form March 26, 2007 